\title{
Triple active antiretroviral regimen including enfuvirtide via the Biojector is effective and safe
}

\author{
Mona Loutfy MD FRCPC MPH, Colin Kovacs MD FRCPC
}

\begin{abstract}
M Loutfy, C Kovacs. Triple active antiretroviral regimen including enfuvirtide via the Biojector is effective and safe. Can J Infect Dis Med Microbiol 2007;18(Suppl A):10A-11A.

For full HIV virological suppression, three fully active antiretroviral agents are required. New drug classes should be included to ensure that agents are fully active. The addition of enfuvirtide and efavirenz to the present patient's new antiretroviral regimen ensured that two fully active agents were in use in the setting of a moderate degree of nucleoside resistance and a high level of protease resistance, and where non-nucleoside reverse transcriptase inhibitors were still fully active. Both viral load and CD4 count responded favourably to this regimen. The patient received support from physicians and clinic staff in the introduction and use of enfuvirtide. To reduce injection site reactions, a needle-free injection system (Biojector) proved effective.
\end{abstract}

Key Words: Antiretroviral agents; HIV fusion inhibitors; HIV infection

Three fully active antiretroviral (ARV) agents are required in an HIV treatment regimen to allow for complete virological suppression in a patient who is ARV naïve or experienced. To ensure that agents are fully active, the inclusion of ARV drugs from as many new classes as possible is important. Studies (1-3) have shown that including at least one drug from a new class with other active agents has beneficial effects. Furthermore, including two ARV agents from two new classes has been shown to be even more effective (4). Including three active ARV agents can be complicated in treatment-experienced patients because the genotype may underestimate the degree of underlying resistance. When using agents such as efavirenz or nevirapine from the non-nucleoside reverse transcriptase inhibitor (NNRTI) class, which have a low genetic barrier in treatment-experienced patients with multiple protease and nucleoside mutations, the inclusion of another new agent from a new class, such as enfuvirtide, is crucial to ensure full virological suppression and to prevent NNRTI resistance. To mitigate the well-known adverse event of injection site reactions (ISRs), subcutaneous administration by the needle-free Biojector injection system (Biojector Medical Technologies, USA) may be considered.

\section{CASE PRESENTATION}

The patient, a 52-year-old man, was likely infected with HIV in 1993, and was diagnosed as HIV positive in 1994. He has had no previous nor current AIDS-defining illnesses, and is negative for hepatitis $\mathrm{B}$ and $\mathrm{C}$.

\section{La trithérapie antirétrovirale active à base d'enfuvirtide administré à l'aide du Biojector est sûre et efficace}

Pour une suppression virologique complète du VIH, trois antirétroviraux entièrement actifs sont nécessaires. De nouvelles classes de médicaments devraient être incluses au schéma thérapeutique pour s'assurer que les agents sont entièrement actifs. L'ajout de l'enfuvirtide et de l'efavirenz au nouveau schéma antirétroviral du présent patient a permis de s'assurer que deux agents entièrement actifs étaient utilisés en présence d'une résistance modérée aux nucléosides et d'une importante résistance à la protéase, alors que les inhibiteurs non nucléosidiques de la transcriptase inverse étaient encore entièrement actifs. La charge virale et la numération des CD4 ont toutes deux répondu favorablement à ce schéma thérapeutique. Le patient a reçu un soutien des médecins et du personnel de la clinique dans l'introduction et l'utilisation de l'enfuvirtide. Afin de réduire les réactions au point d'injection, un système d'injection sans aiguilles (Biojector) s'est révélé efficace.

Before initiating ARV therapy in October 1996, the patient's CD4 count was 300 cells $/ \mathrm{mm}^{3}$ (September 1996). He was initially treated with zidovudine (ZDV) and lamivudine (3TC). This treatment failed (viral load 16,920 copies/mL), and he was switched to a regimen of stavudine (d4T), 3TC and indinavir in March 1997. He subsequently developed kidney stones, and in November 2000, indinavir was replaced with nelfinavir and $\mathrm{d} 4 \mathrm{~T}$ was replaced with ZDV in the treatment regimen. On this regimen, the patient's viral load remained detectable (100 copies/mL in April 2001). Treatment was stopped from May to July 2001, when he became ill with a perforated appendix. Therapy was reinitiated in July 2001 with ZDV, 3TC and nelfinavir. The patient failed to achieve viral suppression and again stopped taking his medication in 2002. His CD4 count nadir was 250 cells $/ \mathrm{mm}^{3}$ in January 2005 and remained so in April 2005 (CD4 13.9\% in May 2005).

In May 2005, the patient was referred to the clinic to assess restarting ARV therapy because prophylaxis measures for Pneumocystis jiroveci pneumonia (PCP) were indicated if further decreases in the percentage of CD4 occurred.

The patient's genotype profile in 2001 showed a high level of protease inhibitor resistance, as indicated by mutations at L10I, K20I, M46L, I64V, A71V, V82A and L90M. The genotype also showed mutations at D67N and K70R, which indicated low levels of resistance to ZDV, abacavir and d4T. Due to prior dual therapy with nucleoside reverse transcriptase inhibitors (NRTIs), it was likely that the patient had more NRTI resistance than genotyping indicated. Patients previously 
treated with mono and dual NRTI therapy have been shown to develop the associated mutations (5-7). Current genotyping techniques detect mutations dependent on current drug pressure and require $10 \%$ to $50 \%$ of the present HIV quasispecies to be carrying the mutation before it can be detected.

It is the authors' practice to insist on a treatment regimen with three active ARV drugs to ensure full suppression and thereby protect the patient from developing resistance to all agents used. A regimen comprising efavirenz, abacavir plus 3TC plus ZDV, and tenofovir was considered, but this regimen has durability issues due to the high level of NRTI resistance. The regimen initiated for the present patient in July 2005 comprised enfuvirtide, efavirenz, abacavir plus 3TC plus ZDV, and tenofovir. Enfuvirtide and efavirenz were two definitely active drugs because they were from new classes, and the combination of NRTIs was considered one active drug. This regimen was chosen particularly to allow for three active drugs and to protect the NNRTI efavirenz. Efavirenz is a highly potent ARV agent but has a low genetic barrier because cross-class resistance to this class develops with a single point mutation (8). If the NRTIs had been given with efavirenz alone, the regimen would have risked virological failure and loss of the ability to effectively treat with the entire class of NNRTIs.

All the patient's therapeutic options were discussed with him, and he agreed to start on the enfuvirtide-containing regimen. He was registered with the Fuzeon Care Program (Hoffmann-La Roche Ltd, Canada) to receive active monitoring and tracking of his enfuvirtide shipments as well as reimbursment coordination for his medication. The patient was trained by a clinic nurse in enfuvirtide administration using a conventional needle.

Following initiation of treatment with enfuvirtide, the patient complained of severe ISRs that lasted between three and seven days; they did not limit his activities but did affect his quality of life due to pain and itchiness. The most affected site was the abdomen due to the presence of an umbilical hernia.

To address these issues, the Biojector administration system for enfuvirtide was presented to the patient as an option. The Biojector is a needle-free injection system that has been shown to deliver enfuvirtide with pharmacokinetics comparable to those with conventional needle delivery (9). The patient consented and was enrolled into a Biojector study in December 2005. He was trained in the use of the Biojector system by a clinic nurse. He was followed up after one month, when he stated his preference for the Biojector over conventional needles. The ISRs after initiation of Biojector use were limited, mainly bruising, and did not affect his daily functioning. Furthermore, the patient's adherence to enfuvirtide treatment was $100 \%$, despite the ISRs.
Shortly after initiation of the enfuvirtide-containing regimen, the patient's viral load dramatically dropped from 80,737 copies/mL in April 2005 to 106 copies/mL in August 2005. In October 2005, the patient achieved maximal viral suppression. His CD4 count increased from 250 cells $/ \mathrm{mm}^{3}$ in April 2005 to 430 cells $/ \mathrm{mm}^{3}$ in October 2005 to 460 cells $/ \mathrm{mm}^{3}$ in August 2006.

In late 2006, the patient's viral load continued to be undetectable and his CD4 count had plateaued at greater than 400 cells $/ \mathrm{mm}^{3}$. Due to his work-related travel, the patient used a combination of the Biojector and a conventional needle system for enfuvirtide administration, and he managed to avoid ISRs.

\section{COMMENTS}

A regimen containing drugs from two new ARV classes (enfuvirtide and efavirenz) effectively reduced this patient's viral load to undetectable levels, and his CD4 count improved. This patient had considerable support from the clinic during and after the introduction of enfuvirtide to his regimen. The severe ISRs experienced by this patient abated with the successful incorporation of the Biojector for administration.

\section{REFERENCES}

1. Lalezari JP, Henry K, O'Hearn M, et al; TORO 1 Study Group. Enfuvirtide, an HIV-1 fusion inhibitor, for drug-resistant HIV infection in North and South America. N Engl J Med 2003;348:2175-85. (Erratum in 2003;349:1100).

2. Lazzarin A, Clotet B, Cooper D, et al; TORO 2 Study Group. Efficacy of enfuvirtide in patients infected with drug-resistant HIV-1 in Europe and Australia. N Engl J Med 2003;348:2186-95.

3. Montaner J, Guimaraes D, Chung J, Gafoor Z, Salgo M, DeMasi R. Prognostic staging of extensively pretreated patients with advanced HIV-1 disease. HIV Clin Trials 2005;6:281-90.

4. Grinsztejn B, et al. Novel integrase inhibitor MK-0518 potent and well tolerated in highly treatment-experienced patients at week 24 . 46th Interscience Conference on Antimicrobial Agents and Chemotherapy. San Francisco, September 27 to 30, 2006. (Abst H-1670B)

5. Hatano H, Hunt P, Weidler J, et al. Rate of viral evolution and risk of losing future drug options in heavily pretreated, HIV-infected patients who continue to receive a stable, partially suppressive treatment regimen. Clin Infect Dis 2006;43:1329-36.

6. Kantor R, Shafer RW, Follansbee S, et al. Evolution of resistance to drugs in HIV-1-infected patients failing antiretroviral therapy. AIDS 2004;18:1503-11.

7. Napravnik S, Edwards D, Stewart P, Stalzer B, Matteson E, Eron JJ Jr. HIV-1 drug resistance evolution among patients on potent combination antiretroviral therapy with detectable viremia. J Acquir Immune Defic Syndr 2005;40:34-40.

8. Bacheler LT, Anton ED, Kudish P, et al. Human immunodeficiency virus type 1 mutations selected in patients failing efavirenz combination therapy. Antimicrob Agents Chemother 2000;44:2475-84.

9. Harris M, Joy R, Larsen G, et al. Enfuvirtide plasma levels and injection site reactions using a needle-free gas-powered injection system (Biojector). AIDS 2006;20:719-23. 


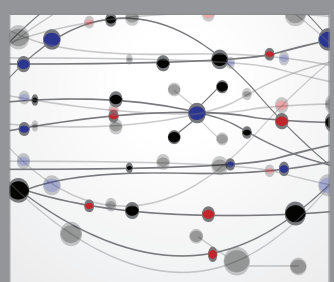

The Scientific World Journal
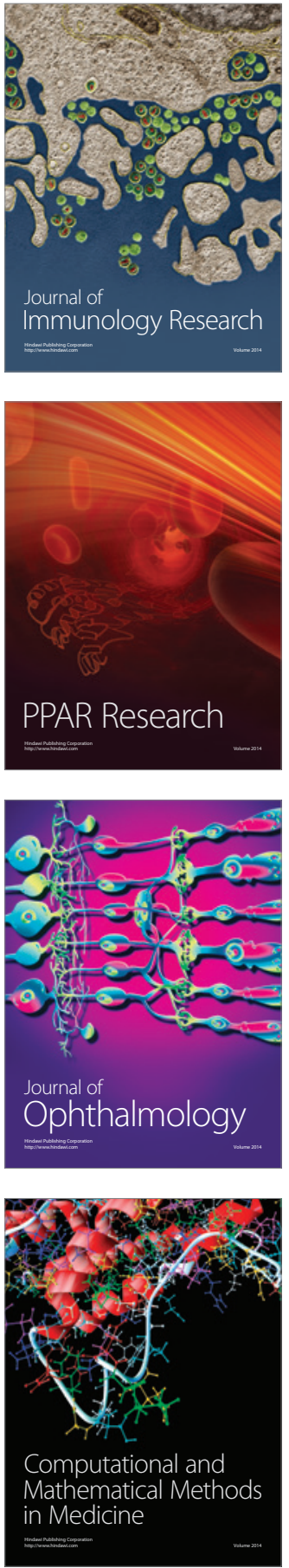

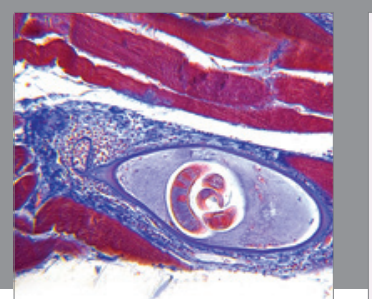

Gastroenterology Research and Practice

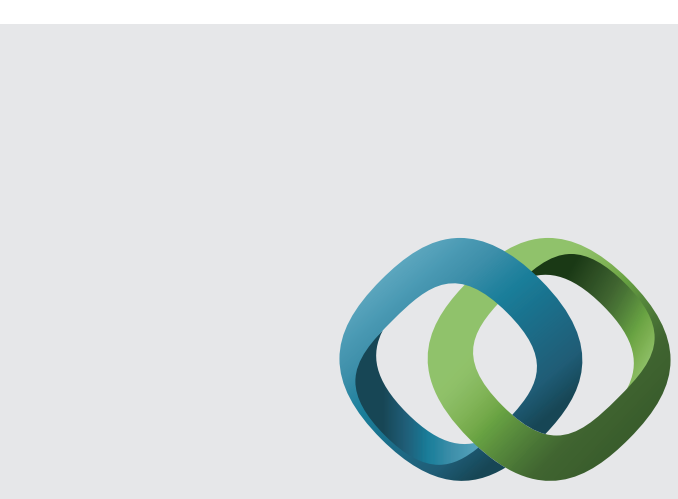

\section{Hindawi}

Submit your manuscripts at

http://www.hindawi.com
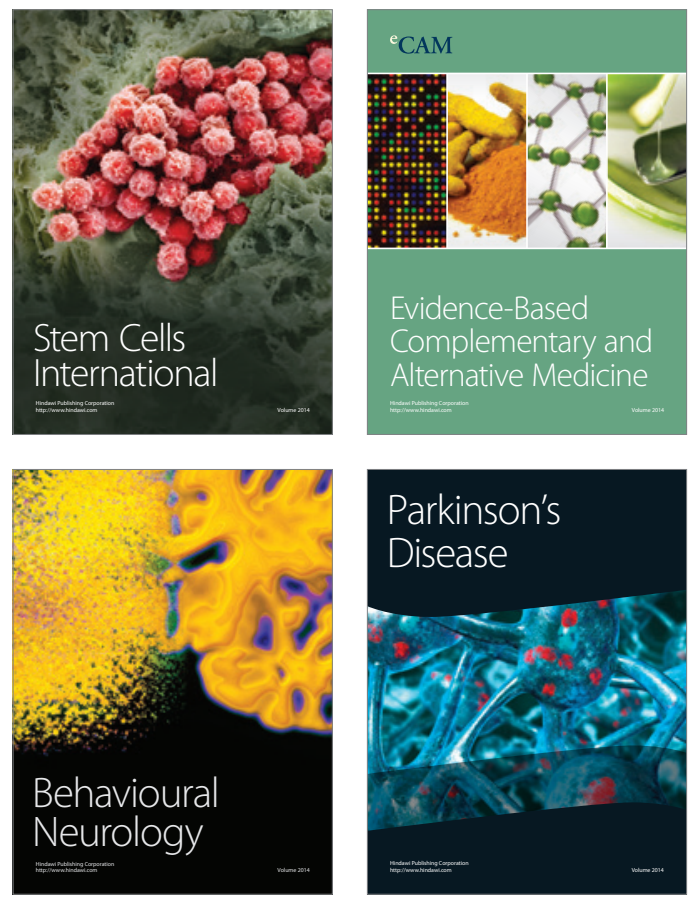
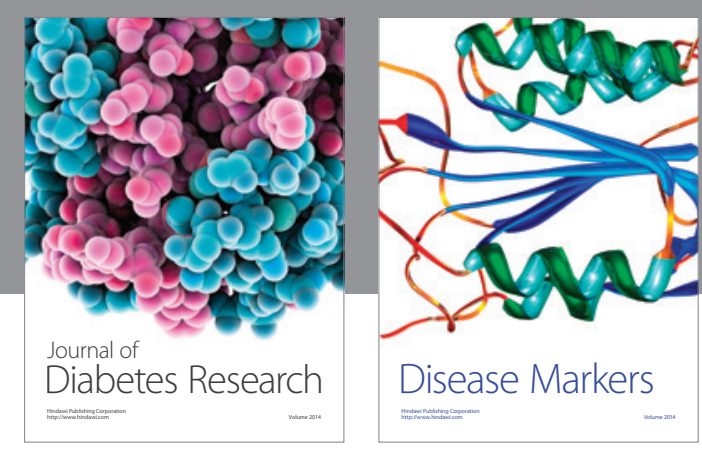

Disease Markers
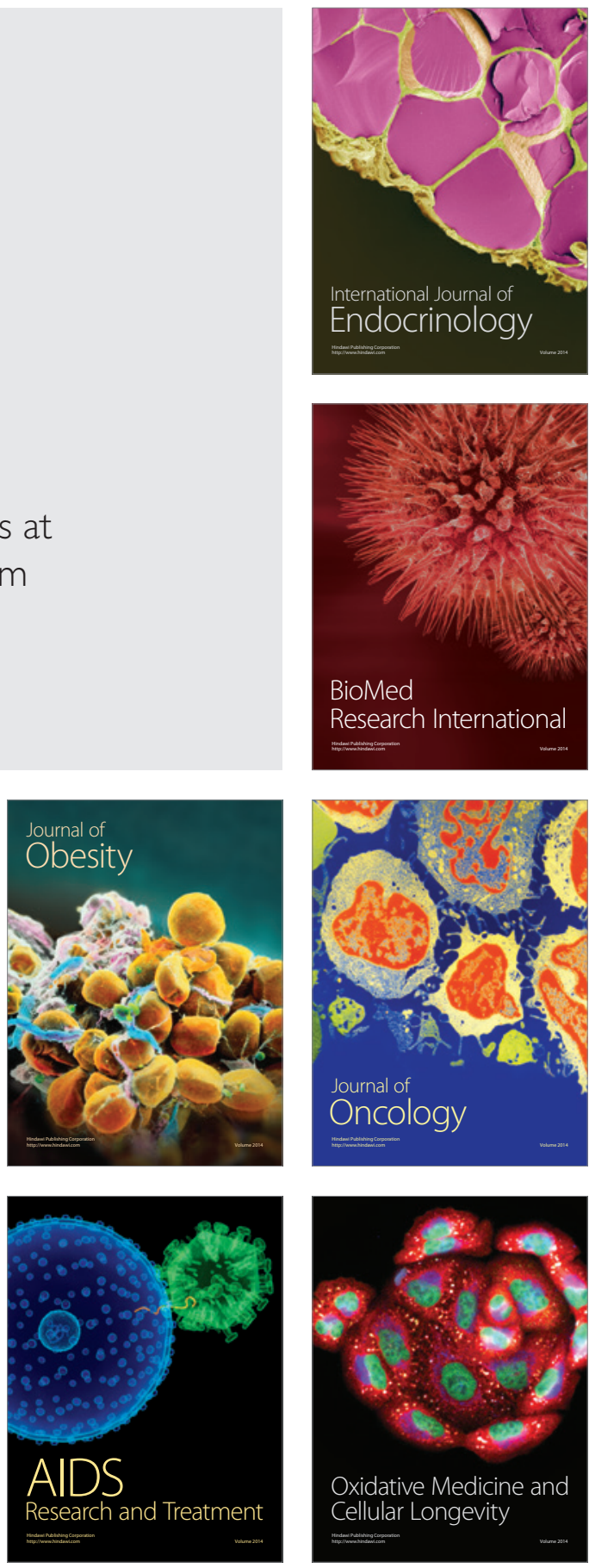